\title{
Yeast-Like Fungi Count
}

National Cancer Institute

\section{Source}

National Cancer Institute. Yeast-Like Fungi Count. NCI Thesaurus. Code C147344.

The determination of the amount of yeast-like fungus present in a sample. 